\title{
Functional Calculation of a Driving Mechanism of a Handling Machine for Disabled Persons
}

Pavol Kurcik, Miroslav Blatnicky, Jan Dizo

Department of Transport and Handling Machines, Faculty of Mechanical Engineering, University of Zilina. Univerzitna 8215/1, 01026 Zilina. Slovak Republic. E-mail: pavol.kurcik@fstroj.uniza.sk, miroslav.blatnicky@fstroj.uniza.sk, jan.dizo@fstroj.uniza.sk

\begin{abstract}
This article deals with state-of-art in the field of handling machines intended for disabled people, which serve for disabled entry of such people and for people with delimited locomotion. It contains calculation of forces, which act in the mechanical system of an electric device during its operation in real conditions, changes of reactions depending on the load and the climbing angle as this solved handling machine will designed for negotiation of staircases. The objective is the functional calculation of a driving mechanism of a stair chair marked SA Alfa, i. e. the calculation of loading forces and their action on the driving mechanism. It will serve in the next step as an input for the calculation of a required power under conditions of occurance of maximal resistance forces, which will be determining factor for dimensioning of driving components of this device.
\end{abstract}

Keywords: Handling machine, Disabled persons, Functional calculation, Driving mechanism

\section{Introduction}

Nowadays, one meets handling machines almost at every turn. Handling machines are used not only in industry or in transport, but thew have found thein application in such fields as health service, what manipulators servis for manipulation of disabled poeple and poeple with delimited locomotion prove. Present state of handling machines in the field of using for disabled poeple brings solutions for number of daily problems, what disable poeple have to face [1]. The unexpected and large lost of mobility can cause serious chase of a human life, but it ussualy affets also a common day of members of family, because halp of them even for simply activieites is necessary. Therefore, disabled poeple depend on help of members of family also for actions of movement from place to place. Such activities can cause number of troubles, for which the help of a close person may not even be adequate. The passing of difference in elevation is the typice example, which disable poeple have to face. While public buildings, such as hospitals, burnues etc. are equipped with lifts and ramps, staircases of housing units, family houses and also often staircases in buildings of companies are not customized for locomotion of disabled people [2, 8]. While poeple with disabled lower part of a body have ussualy better motoric of upper part of a body, what allows them to manage at least particular activities, saddling up and getting up a wheelchair, sadding up and petting up a bed etc., poeple suffering from more signifiant imobility have signifiant troubles. The fiction of handling machines for diabled poeple is to make easier or completely eliminace daily problems, which hinder a full-value life.

\section{SA Alfa staircase chair}

Staircase chairs (or chair lift) are devices, which are mainly intended for poeple suffering from troubles of locomotion organs. The main purpose of a staircase chair is to trasport a person safely and effective to indivitual locations, and concurrently it should occupate with its dimensions a space as little as possible in order to avoid to be a hidrance for movement of people on a staircase.
From the design of a device ut follows, that a person, who uses such a device, has to dispose with a particular mobility needed for saddling up and getting up. For this reason, there is necessary to notice, taht a staircase chair produced in current design is not suitable for manipulation with persons locomoting only on a wheelchair. The track, on which it moves, is very similar to the track of staircase platforms. There is possible to meet most often with circular cross-section profiles, which pattern the shape of a staircase. In case of drivetrain by means of a tow rope pipes are used as a guidance, which are open from the bottom side and a rop efor a drivetrain is placed in them. However, such a technical solution is not satndard for staircase chairs. Diving mechanism with gear wheel is used in much greater extent [12]. In comparison with staircase pratforms, kinds of design of staircase chairs are much various. There are often applicated tracks only with one profile, which serves as a guidance and simultaneously as a drivetrain. In such type of of giudances profiles are usually made of alluminium due to its lower density and sufficient mechanical properties. Some types of tracks represent a modular system, which consists of several short track sections. A simple mounting and possibility of using standardized elements is its main advantage. The guidance is mounted into walls of a staircase or there are used columns mounted directly into stairs. The guidance can be located in inner or outer side of a staircase. The SA Alfa staircase chair is intended for the mounting in interiors of buildings, mainly for every types of staircases. The maximal climbing angle of $52^{\circ}$ is only one limited factor of its installation. The control of the chair is ensured by means of lever controller located in one armrest according to customer's requirements. Calling the chair is possible in end positions using wall controller. One can also control the chair by means of a remote control. The SA Alfa staircase chair is designed primary to be mounted in houses, therefore it is equipped with large number of safety facilities, among others safety edges of drivetrain unit, safety edges of a trolley, safety edges of footrests and safety belt. For such cases, the chair would not stop in the end position, safety backstops are 
monted on the track. From the reason of saving the space in a staircase, armrests, footrests and the seat are tilted. The latest types of the chair have automated tilting of footrests. The seat is possible to rotate in end positions, that a person leaves it on the even floor. This rotating is also possible to control using the remote control. The drivetrain of the chair is ensured by means of an electromotor, a gearbox and a gear wheel. The gear wheel rotates on a gear rack. The electromotor is powered by mean of two batteries placed in the body of the chair. Bateries are charged in end positions of the chair.

\section{Estamination of the resistance forces}

For calculation of the driving mechanism of the staircase as well as other devices moving with a load on a particular track the estamination of gravitational forces and loading forces is necessary. Equally important there is necessary to take into account the incluence of the geometry of a device on magnitude of forces, since the magnitude and direction of a transmitted load must correspond with the type of the contact of wheels, which are in the contact with the track $[4,6,7,13]$. If the geometry in the contant of guiding wheels and the track is designed inappropriately, passive resistances will rise due to higher loading. It will result to more massive of wear of used elements, increased risk of failures and last but not least to need of more powerful drivingtrain for ensuring of the smooth movement of the used mechanism. During operation of the stairchair various types of resistance forces act on the structure, which have to be overcome, that the chair will be set in motion. The device moves on the track with the considerable climbing. Therefore, the resistance force due to gradient of a slope is the most significant quantity acting against moving of the chair.

Gradient resistance is the function of gradient of the track. In case of the horizontal track, this angle equals $0^{\mathrm{O}}$ and the gradient resistance also equals $0 N$ (we assume the rigid track). If the flexible track is considered, this force results to deflection of a beam, but its value is much smaller in comparison with the maximal gradient. We assume the track as one entirety with sufficient rigidity and hence the resulting gradient resistance $F_{R G}$ is given by the following formulation:

$$
F_{R G}=F_{Q} \cdot \sin \alpha[N]
$$

where:

$F_{Q} \quad$ gravitational force of the chair load $[N]$,

$\alpha \quad$ angle of gradient $\left[{ }^{\mathrm{O}}\right]$.

In the contact of the chair with the track polyamide guidance wheels are used. They serve for transmitting the load to the track structure. Wheels are monted in pins, in which friction is generated. Value of this resistance is determined by the normal force transmitted by the wheel, friction coefficient between the pin surface and material of the wheel, and the friction circle of radius [3, 7, 14]. During transmission of power, various types of wheels are in engaging movement, namely the wheel mounted in friction bearings and the wheel mounted in steel pins with lubricant. The value of resistance generated by friction in the slide assembly can be expressed by means of the friction force $F_{F}$ acting against movement or by the moment of the friction circle of radius $M_{F}$ :

$$
F_{F}=\frac{F_{1} \cdot f_{F} \cdot r_{F}}{R}[N],
$$

or

$$
M_{F}=F_{1} \cdot f_{F} \cdot r_{F}[N \cdot m],
$$

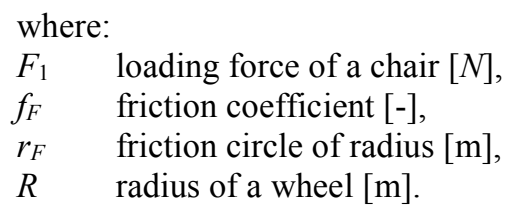

Rolling resictance is generated as a results of deformation of used material in the contact of the wheel with a surface. In the real case, deformation occures on the wheel and on the surface as well, while the value of deformation depends on marial properties and on the value of the transmitted load. Due to this prescribed deformation, the normal reaction will not act in the axis of the wheel perpendicular to the surface, but it will be adjusted by the value $e$. by this reason, there is formed the moment acting opposite to the considered direction of movment or opposite to driving moment, if driving wheels are considered. Within these acting resistances the rolling resistance is the smallest among other assumed resistances. The rolling resistance can be determined as the force $F_{R R}$ of as the moment of the resistance $M_{R R}$ :

$$
F_{R R}=N_{1} \cdot \frac{e}{R}[N]
$$

or

$$
M_{R R}=N_{1} \cdot e[N \cdot m],
$$

For calculation of resistances acting against the chair movement there is necessary at first to determine all reactions caused by the chair mass and by the load of a sitting person. A simplified model is used for calculation of these forces with labelling of forces acting on the chair. From the change of rotation of wheelchairs point of view there is needed to prescribed constant distances and distances depending on the angle of gradient. The vertical load is transmitted by the lower trolley, i. e. the reaction $R_{a z}$, which is located in the common plane of forces $Q$ and $G$. It is valid for any position of wheelchair rotation. This force will be decomposed into two components, i. e. normal, which is perpendicular to the track and to the other, which is marked as the gradient resistance (parallel with the track), in compliance with change of the angle of gradient of the track and therefore also with the rotation of the trolley. As the resulting force of the gravity of the chair and a person mass does not act in the assumed line connecting centres of tubes of the track, the overturning moment is formed. This negative effect both trolleys compensate by the couple of forces.

Equilibrium equations are used for determining described forces above. Given that the distance between 
both reactions is not constant but it is changing during operation of the chair, the dependace of these change have to be determined.

Equilibrium forces in the $z$ axis are:

$$
\sum F_{i z}=0 \Rightarrow R_{A Z}-G-Q=0,
$$

and equilibrium of moments about the point $A$ :

$$
\sum M_{i A}=0 \Rightarrow R_{B Y} \cdot 285-G \cdot 119-Q \cdot 180=0,
$$
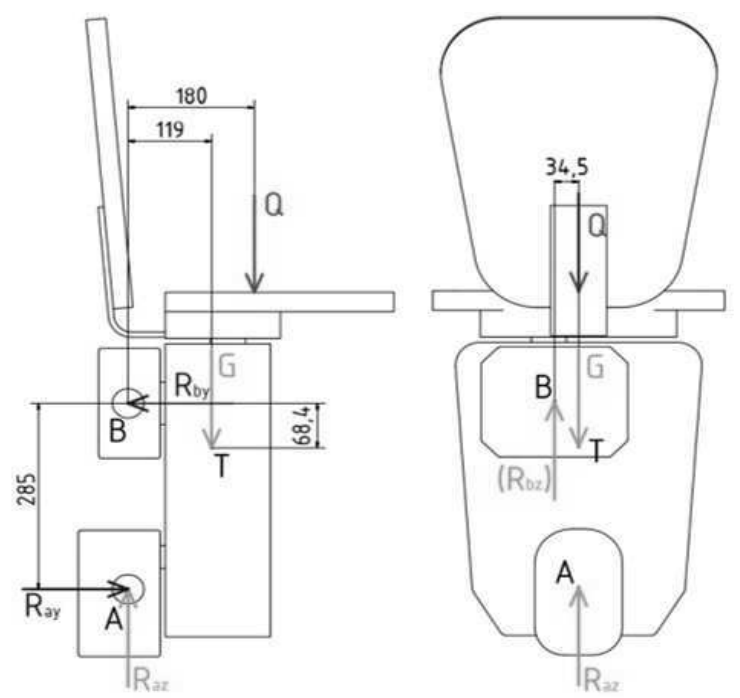

Fig. 2 The geometry of the stair chair and action of force on the stair chair
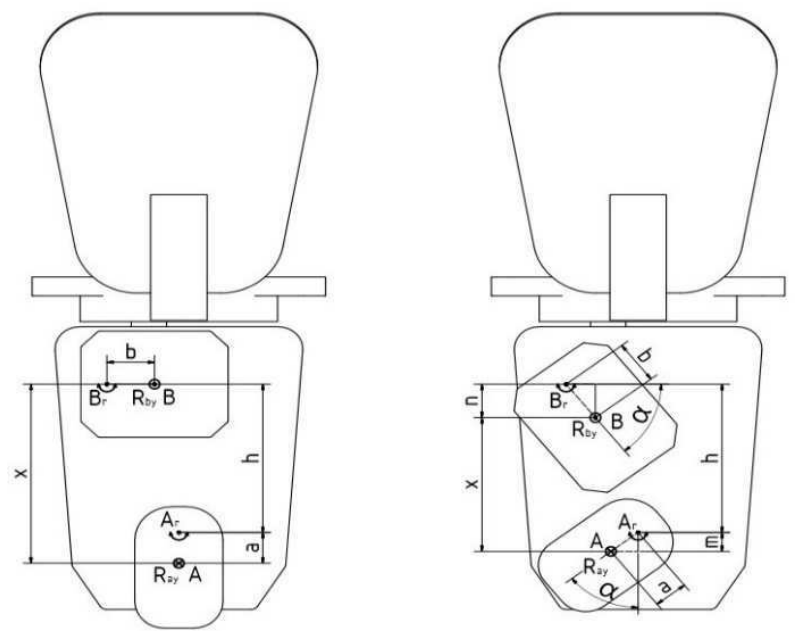

Fig. 3 The geometry of guiding trolleys when moving on the straight track (left) and when guiding trolleys are inclined

From it the reaction $R_{b y}$ results as follow:

$$
R_{B Y}=\frac{G \cdot 119+Q \cdot 180}{285},
$$

Equilibrium forces in the $y$ axis are:

$$
\begin{gathered}
\sum F_{i y}=0 \Rightarrow R_{A Y}-R_{B Y}=0 \\
R_{A Y}=R_{B Y}
\end{gathered},
$$

Operation of the chair is performed on the track with a certain gradient. Hence, it results to rotation of trolleys. As centres of rotation of trolleys are not coincident with points of forces $R_{b y}$ and $R_{a y}$, the distance between reactions and their values are being changed. Th eraction $R_{a y}$ is decomposed on a normal and a tangential component (i. e. a gradient resistance). The distance of thesereaction is marked as $x$ and this value varies depending on angle of gradient $\alpha$ of the track. The increasing of the angle of gradient causes reducing of the distance between reactions, which results to increasing of reactions $R_{b y}$ and $R_{a y}$. For calculation of the distance $x$ there is necessary to determine constant and variable values of distances (Fig. 3) and based on this to define the change of the distance $x$ as a function of the angle $\alpha$.

Variables $m$ and $n$ can be defined from a right triangle, as distances $a$ and $b$ are constant and they result from trolleys design:

$$
\begin{gathered}
m=a \cdot \cos \alpha, \\
n=b \cdot \sin \alpha .
\end{gathered}
$$

The distance $x$ is determined as:

$$
x=h-n+m \text {. }
$$

Substituting eqs. (9) and (10) into (11) results:

$$
x=h-b \cdot \sin \alpha+a \cdot \cos \alpha .
$$

The direction of acting of the reaction is the same as in the case of zero gradient of the track (Fig. 2). In the calculation there is necessary to cinsider the variable distance $x$ :

$$
\begin{gathered}
\sum M_{i A}=0 \Rightarrow R_{B Y} \cdot 285-G \cdot 119-Q \cdot 180=0, \\
R_{b y}=\frac{G \cdot 119+Q \cdot 180}{x}=\frac{G \cdot 119+Q \cdot 180}{h-n+m}, \\
R_{b y}=\frac{G \cdot 119+Q \cdot 180}{h-b \cdot \sin \beta+a \cdot \cos \alpha} . \\
\sum F_{i y}=0 ; \Rightarrow R_{a y}-R_{b y}=0 \\
R_{a y}=R_{b y} .
\end{gathered}
$$

The force is being decomposed in the normal and tangential components considering the track, whereby, the summary vector of these components perpendicular each other equals to the force $Q+G$ (the force $R_{A Z}$ in case of the straight track):

$$
\begin{gathered}
F_{n a}=(G+Q) \cdot \cos \alpha, \\
F_{s}=(G+Q) \cdot \sin \alpha .
\end{gathered}
$$

In case of determination of the power of the electromotor there is necessary to consider all resistance forces acting retrogate of the designed device. For calculation of these forces there is necessary to determine normal forces acting on guidance wheels. Properties of used material directly influence values of resistances, mainly a value of friction between elements moving on each other. Reliability of the calculation of the power of a drive motor requires taking into account all factors influencing values of the forces on the drive-train and guidences. The normal 
force transimitted by wheels will increase due to the position of travelling wheels angle-wise in case of the upper guidance (Fig. 4). The vertical force transmitted on the lower guidance is decomposed into two components. One component represents the gradient resistance $\left(F_{s}\right)$ and the other (normal component $F_{n a}$ ) represents the rolling resistance and the resistance generated by friction. The reaction $R_{a y}$ corresponds with the direction of the acting force and therefore values of resistances on guiding rolls is calculated directly from this reaction.

$$
\begin{gathered}
\sum F_{i y}=0 ; \Rightarrow 2 \cdot F_{n b} \cdot \sin \beta-R_{b y}=0, \\
F_{n b}=\frac{R_{b y}}{2 \cdot \sin \beta} . \\
F_{n b}=\frac{G \cdot 119+Q \cdot 180}{2 \cdot \sin \beta \cdot(h-b \cdot \sin \alpha+a \cdot \cos \alpha)} .
\end{gathered}
$$

As the resistance generated by friction and the rolling resistance depend on the normal force, we can express them in a common formulation:

$$
\begin{gathered}
F_{o}=\frac{2 \cdot F_{n}}{d_{i}} \cdot\left(e+r_{\check{c}} \cdot f_{\check{c}}\right), \\
M_{o}=F_{n} \cdot\left(e+r_{\check{c}} \cdot f_{\check{c}}\right),
\end{gathered}
$$

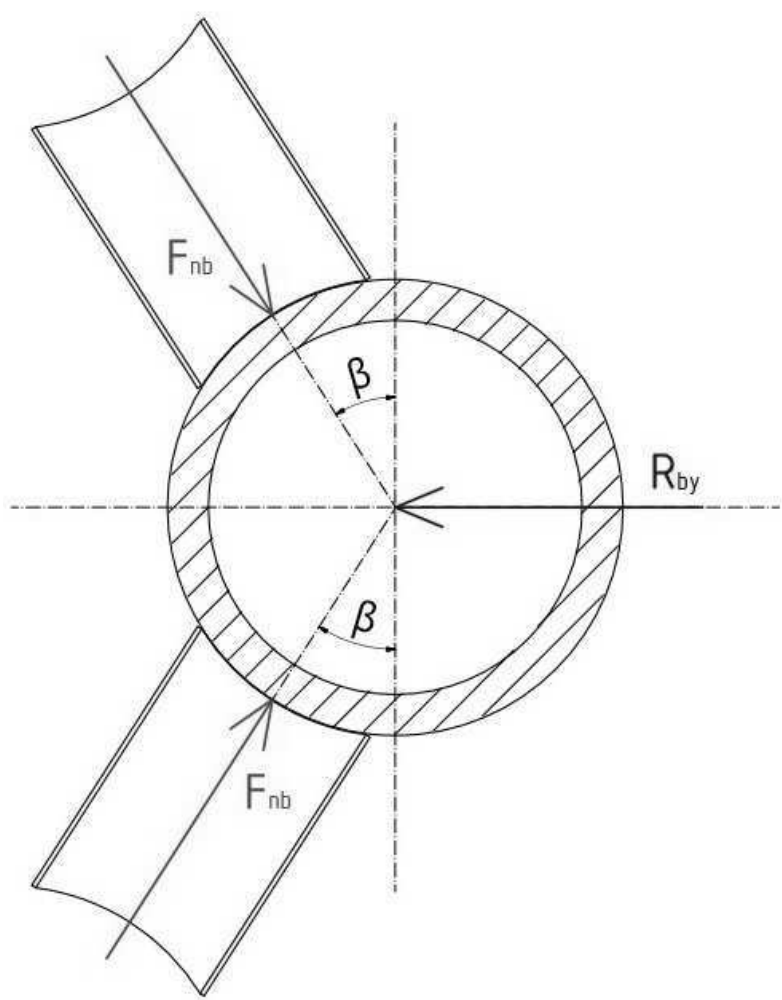

Fig. 4 Normal forces of wheels of the upper guidance

The resistance of guiding wheels of the upper guidance (Fig. 5):

- Formulation using the force:

$$
F_{o b}=2 \cdot \frac{2 \cdot F_{n b}}{d_{b}} \cdot\left(e_{b}+r_{c} b \cdot f_{c b}\right),
$$

$$
F_{o b}=\frac{2 \cdot(G \cdot 119+Q \cdot 180) \cdot\left(e_{b}+r_{c b} \cdot f_{c b}\right)}{d_{b} \cdot \sin \beta \cdot(h-b \cdot \sin \alpha+a \cdot \cos \alpha)},
$$

- Formulation using the moment:

$$
\begin{gathered}
M_{o b}=2 \cdot F_{n b}\left(e_{b}+r_{c b} \cdot f_{c b}\right), \\
M_{o b}=\frac{(G \cdot 119+Q \cdot 180) \cdot\left(e_{b}+r_{c b} \cdot f_{c b}\right)}{\sin \beta \cdot(h-b \cdot \sin \alpha+a \cdot \cos \alpha)} .
\end{gathered}
$$

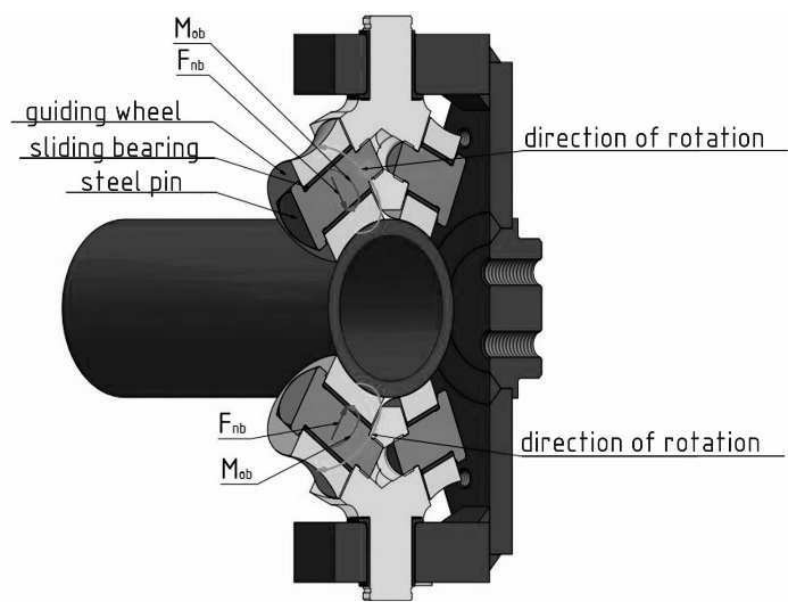

Fig. 5 Display of passive resistances of wheels of the upper guidance

The resistance of guiding rollers of the lower guidance due to the reaction $R_{a y}$ (Fig. 6):

- Formulation using the force:

$$
\begin{gathered}
F_{o a v}=\frac{2 \cdot R_{a v}}{d_{a 1}} \cdot\left(e_{a v}+r_{\check{c} a v} \cdot f_{\check{c} a}\right) \\
F_{o a v}=\frac{2 \cdot(G \cdot 119+Q \cdot 180) \cdot\left(e_{a v}+r_{\check{c a v}} \cdot f_{\check{c} a}\right)}{d_{a v} \cdot \sin \beta \cdot(h-b \cdot \sin \alpha+a \cdot \cos \alpha)}
\end{gathered}
$$

- Formulation using the moment:

$$
\begin{gathered}
M_{o a v}=R_{a y}\left(e_{a v}+r_{\check{c} a v} \cdot f_{\check{c} a}\right), \\
M_{o a v}=\frac{(G \cdot 119+Q \cdot 180) \cdot\left(e_{a v}+r_{\check{c} a v} \cdot f_{\check{c} a}\right)}{h-b \cdot \sin \alpha+a \cdot \cos \alpha} .
\end{gathered}
$$

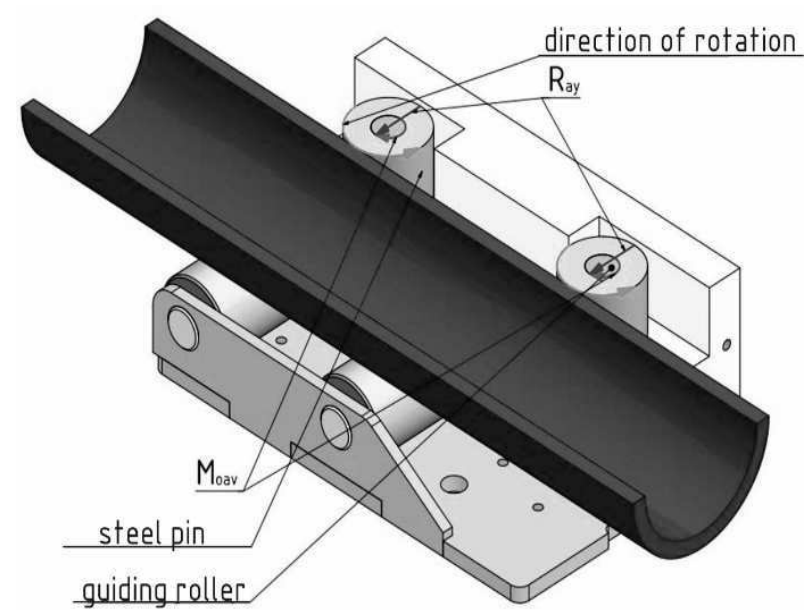

Fig. 6 Display of passive resistances of guiding rollers of the lower guidance 
The resistance of the guiding pulley transmitting the vertical load (Fig. 7):

- Formulation using the force:

$$
\begin{gathered}
F_{o a k}=\frac{2 \cdot F_{n a}}{d_{a 2}} \cdot\left(e_{a k}+r_{\check{c} a k} \cdot f_{\check{c} a}\right), \\
F_{o a k}=\frac{2 \cdot(G+Q) \cdot \cos \alpha}{d_{a k}} \cdot\left(e_{a k}+r_{\check{c} a k} \cdot f_{\check{c} a}\right),
\end{gathered}
$$

- Formulation using the moment:

$$
\begin{gathered}
M_{o a k}=F_{n a} \cdot\left(e_{a k}+r_{c a k} \cdot f_{\check{c a}}\right), \\
M_{o a k}=(G+Q) \cdot \cos \alpha \cdot\left(e_{a k}+r_{\check{c a k} \cdot} \cdot f_{\check{c} a}\right),
\end{gathered}
$$

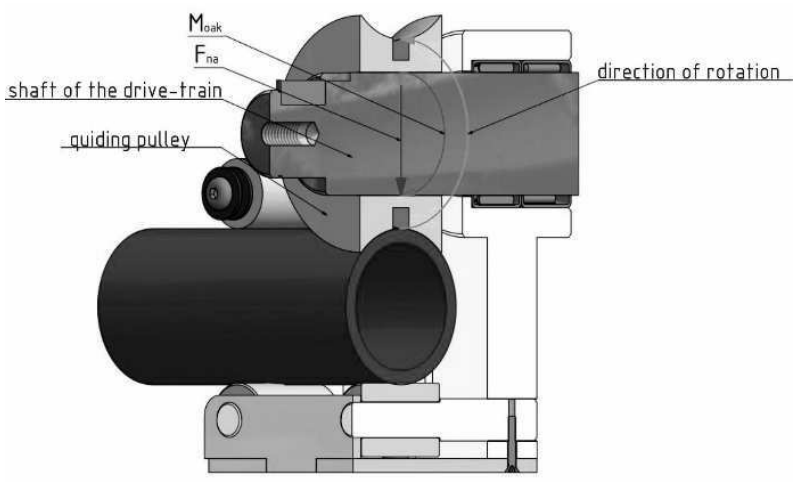

Fig. 7 Display of passive resistances of guiding pulley of the lower guidance

The gradient resistance (Fig. 8):

- Formulation using the force:

$$
F_{s}=(G+Q) \cdot \sin \alpha,
$$

- Formulation using the moment:

$$
M_{s}=\frac{d}{2} \cdot(G+Q) \cdot \sin \alpha \text {. }
$$

where $d$ is a diameter of the pitch circle of the pinion gear $[\mathrm{mm}]$.

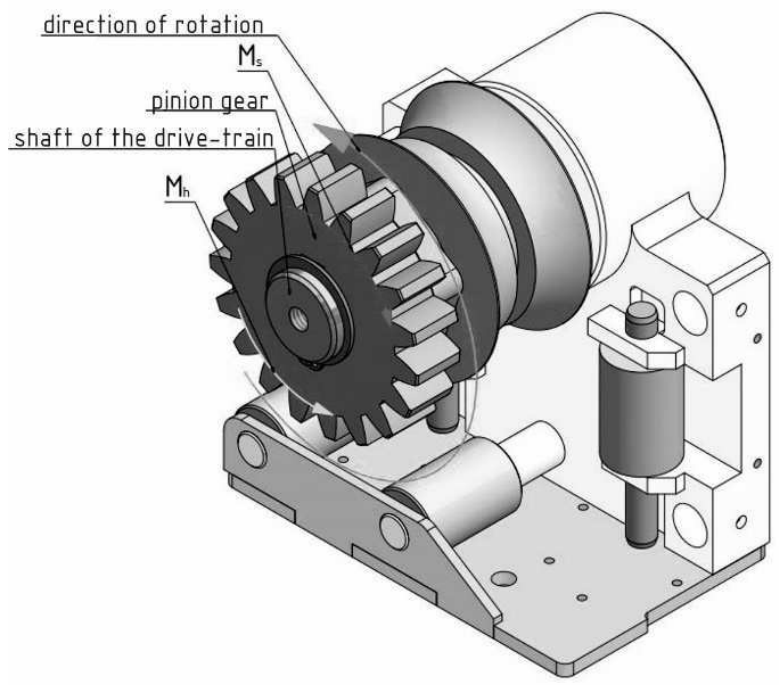

Fig. 8 Display of the gradient resistance when the stair chair is climbing

\section{Other aspects for calculation of the power of the used drive motor}

Calculation of the power of the electromotor consists of several variable and constant values. In terms of design, there is possible to produce the track with the maximal gradient of $52^{\circ}$, which represents the first boundary condition for the calculation. The maximal load capacity of $130 \mathrm{~kg}$ is the second one. The speed of the device, which achieves the value of $0.1 \mathrm{~m} \cdot \mathrm{s}^{-1}$, is the third one. The track of the stair chair is made of S235JRG1 steel formed in required shape using modern methods [15], treated with Komaxit powder surface treatment on combination of light aluminium alloys for particular parts [11]. It ensures the surface resistant to mechanical damage, excellent durability and chemical resistance. Forasmuch as the colour is hardened and its thickness is negligible, it can be assumed, it will not influence significantly to the value of the rolling resistance. The gear rack is part of the track made of C16E steel with the module of $3.5 \mathrm{~mm}$.

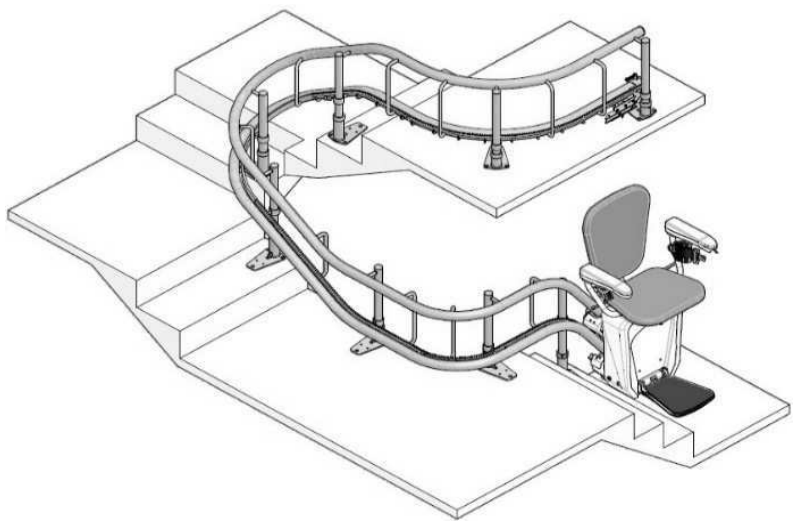

Fig. 9 Shapes of curvatures of the track of the SA Alfa stair chair

Calculation of resistances requires introducing certain constants in equations $1-26$, namely values of the friction circle of radius $\mathrm{r}_{\mathrm{c}}$, values of friction coefficient $f_{c}$ and a lever arm of rolling friction $e$. The friction circles of radius are determined from the design of guiding parts of both trolleys. Particular radii result from the geometry and equal $r_{c a v}=4 \mathrm{~mm}, r_{c a k}=17.5 \mathrm{~mm}$ and $r_{c b}=5.95 \mathrm{~mm}$. In calculations we consider two values of friction coefficients. For guiding wheels of upper guidance the value $f_{c b}=0.04$ is considered. Considering values in tables for friction coefficients do not contain large combination of materials, e. g. polyamide - steel, we take into account values of sliding friction with greasing. For combination of polyamide - steel values from 0.04 to 0.2 are valid. As values of friction coefficients are lower then values for sliding friction, we consider the value of friction coefficient $f_{c a}=0.1$. The friciton circle of radius relates with deformation of s surface and with material of the guiding part. These values are determined from the friction circle of radius for a unit radius of a wheel. For the wheel radius of $1000 \mathrm{~mm}$ the friction circle of radius equals to $2 \mathrm{~mm}$. From the ratio of these values there were determined lever arms of rolling friction for guiding rollers of the lower guidance $e_{a v}=0.021 \mathrm{~mm}$ and for the guiding pulley of the lower guidance $e_{a k}=0.07 \mathrm{~mm}$ and for guiding wheels of 
the upper guidance $e_{b}=0.03 \mathrm{~mm}$. Distances $a, b$ and $h$ shown in Fig. 4 are constant and result from the technical solution of the stair chair. For this particular case are valid values: $a=49 \mathrm{~mm}, b=67.5 \mathrm{~mm}$ and $h=236 \mathrm{~mm}$.

The future research in this field will be focused on creation of computational model of the staircase chair for stress analzses of most loaded parts and optimiyation of the structure [5] as well as on setting up multibodz model of the staircase chair in order to investigate dynamic properties of it, which would help to find changes of load under dynamic effects, evaluate accelerations on a chair for investigation of comfort $[9,10]$ for person etc.

\section{Conclusion}

In this article the problem of state-of-art in handing machines for disabled people is described. The mathematical analysis of the function calculation of the drivetrain of the SA Alfa stair chair was the main goal. Subsequent calculation of loading forces and their acting on the mechanism of the device was performed. By substituting of presented values there is possible to calculate all important load forces, which enter into equation for calculation of the needed power of the electromotor used as a source of drive-power of the whole mechanism. This will serve as the input for future research of the presented work for calculation of the needed power under conditions of greates resistance forces. They will be determining factors for dimensioning the driving components of this device on one hand from the safe operation point of view as well as on the other hand from the optimisation point of view in order to diminish the production costs.

\section{Acknowledgement}

This work was supported by the Cultural and Educational Grant Agency of the Ministry of Education of the Slovak Republic within the project No. KEGA 007ŽU4/2017: Modernization of the Vehicles and engines study program.

\section{References}

[1] BEHERA, P.K., GUPTA, A. (2018). NOvel desing of stair climbing wheelchair. Journal of $\mathrm{Me}$ chanical Science and Technology, Vol. 32, No. 10, pp. $4903-4908$.

[2] BOYCE, M.W., AL-AWAR SMITHER, J., FISHER, D.O., HANCOCK, P.A. (2017). Design and instructions for evacuatins disabled adults. Applied Ergonomics. Vol. 58, pp. 48 - 58.

[3] GERLICI, J., GORBUNOV, M., KRAVCHENKO, K., DOMIN, R., KOVTANETS, M., LACK, T. (2017). Slipping and Skidding occurrence probability decreasing by means of the friction controlling in the wheelbreaking pad and wheel-rail contacts. Manufacturing Technology, Vol. 17, No. 2, pp. 179 - 186.
[4] GERLICI, J., LACK, T. (2009). Iterative method for railway wheel profile design. Komunikacie, Vol. 11, No. 2, pp. 49 - 56.

[5] HARUŠINEC, J., MAŇUROVÁ, M., SUCHÁNEK, A. (2016). Optimization of a brake unit in terms of control range. Manufacturing Technology, Vol. 16, No. 5, pp. 917 - 923.

[6] HAUSER, V., NOZHENKO, O.S., KRAVCHENKO, K.O., LOULOVÁ, M., GERLICI, J., LACK, T. (2017). Impact of wheelsets steering and wheel profile geometry to the vehicle behaviour when passing curved track. Manufacturing Technology, Vol. 17, No. 3, pp. 306 312.

[7] HAUSER, V., NOZHENKO, O.S., KRAVCHENKO, K.O., LOULOVÁ, M., GERLICI, J., LACK, T. (2017). Proposal of a mechanism for setting bogie wheelsets to radial position while riding along track curve. Manufacturing Technology, Vol. 17, No. 2, pp. 186 - 192.

[8] KULIGOWSKI, E., PEACOCK, R., WIESS, E., HOSKINS, B. (2015). Stair evacuation of poeple with mobility impairments. Fire and Materials. Vol. 39, No. 4, pp. $371-384$.

[9] LACK, T., GERLICI, J. (2008). Analysis of vehicles dynamic properties from: The point of view of passenger comfort. Komunikacie, Vol. 10, No. 3 , pp. $10-18$.

[10] LOULOVÁ, M., SUCHÁNEK, A., HARUŠINEC, J. (2017). Evaluation of the parameters affecting passenger riding comfort of a rail. Manufacturing Technology, Vol. 17, No. 2, pp. $224-231$.

[11] PASTIRČÁK, R., ŠČURY, J., MORAVEC, J. (2017). The effects of pressure during the crystallization on properties of the AlSi12 alloy. Archives of Foundry Engineering. Vol. 17, No. 3, pp. $103-106$.

[12] RAO, P.K.V. (2018). Design of stair-climbing wheelchair using tri-wheel mechanism. International Journal of Mechanical and Production Engineering Research and Development. Vol. 8, No. 4, pp. $685-694$.

[13] SMETANKA, L., ŠTASTNIAK, P. (2017). Analysis of contact stresses of theoretical and worn profile by using computer simulation. Manufacturing Technology, Vol. 17, No. 4, pp. $580-585$.

[14] SMETANKA, L., ŠŤASTNIAK, P., HARUŠINEC, J. (2018). Wear research of railway wheelset profile by using computer simulation. MATEC Web of Conferences, Vol. 157.

[15] ZRAK, A., MEŠKO, J., MORAVEC, J., NIGROVIC, R., KADÁŠ, D. (2016). Contactless thermal bending of steel sheets. Manufacturing Technology. Vol. 16, No. 1, pp. 309 - 313. 